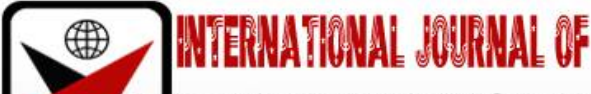

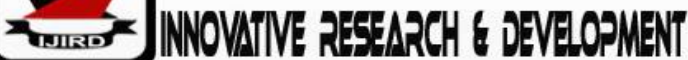

ISSN 2278 - 0211 (Online)

\section{Oral Communication Challenges Encountered during the Instruction of English Language in Secondary Schools in Kenya}

\author{
Joseph K. Kabellow
Ph.D. Researcher, Department of Curriculum Instruction and Educational,
School of Education, Moi University, Kenya
Carolyne Omulando
Dean, School of Education and Social Sciences, Alupe University College, Kenya
Peter L. Barasa
Deputy Principal, Department of Academic and Research, Alupe University College, Kenya
}

\begin{abstract}
:
Oral language is the primary medium through which classroom discourse takes place. It therefore plays a critical role in classroom instruction. This paper examined the oral communication challenges encountered during the instruction of English language classes in secondary schools in Kenya. The study was based on the interaction hypothesis by Michael Long which offers an explanation how ESL learners can best succeed at learning a target language. Embedded within pragmatism as the research philosophy and the descriptive survey design, the study utilized mixed methods approach to collect and analyze both qualitative and quantitative data. Thirteen form three classes randomly selected were observed, thirteen teachers of English language purposefully selected were interviewed and finally 195 students randomly selected from the observed classes filled the student questionnaire. It was established that the most common oral communication challenges faced by learners in secondary school are difficulty pronouncing certain English words, uneven participation in class, and dominance of classroom discourse by a few learners and failure by the learners to seek for clarification or ask questions from their teachers.
\end{abstract}

Keywords: oral communication challenges, instruction of English language, classroom interaction, classroom discourse

\section{Introduction}

Oral skills are an important feature in the interactive language classrooms. They involve listening and speaking. However, non-verbal language for example, eye contact, nodding of the head facial expression and many others are also considered to be part of oral skills. Teachers of any language should strive to develop their learners' oral skills as this will go a long way in developing the learners' communicative competence.

Morreale, Osborn and Pearson (2000) point out that competence in oral communication- in speaking and listening- is a prerequisite to student's academic, personal, and professional success in life. It can be observed that teachers deliver most instructions for classroom procedures orally to students. Students with ineffective listening skills fail to absorb much of the material to which they are exposed. Aleksandrzak (2011) points out that speaking is generally perceived as the most fundamental skill to acquire. She further observes that since the onset of the communicative era it has been treated as the ultimate goal of language training and its proper development has become the focus of attention of both teachers and learners.

According to Shteiwi and Hamuda (2016) speaking is considered to be an important factor in language learning. It is one of the four language skills: speaking, listening reading and writing. Speaking skills are important because they represent someone's knowledge about the languages they know. Citing Davies and Pearse (2000), Shteiwi and Hamuda (2016) point out that the major goal of all English language teaching process should give the learners the ability to use English effectively and accurately in communication. This can only be achieved through the use of appropriate learning techniques and oral skills.

When a learner masters oral skills appropriately in the target language he/she will develop communicative competence. According to Yule (2010) communicative competence can be defined as the general ability to use language accurately, appropriately and flexibly. He further points out the components of communicative competence. The first component is grammatical competence, which involves the accurate use of words and structures. Concentration on grammatical competence only, however, will provide the learner with the ability to interpret or produce L2 expressions appropriately. The ability to use appropriate language is the second component, called social linguistic competence. The learner has to become familiar in the cultural context of the L2 if the learner is to develop sociolinguistic competence.

The third component is called strategic competence. This is the ability to organize a message effectively and compensate via strategies for any difficulties. In L2 use, learners inevitably experience moments when there is a gap 
between communicative intent and their ability to express their intent. Some learners may just stop talking (bad idea), whereas others will try to express themselves using communicative strategy (good idea). This study was set out to investigate oral communication challenges in English language classes in secondary schools in Kenya.

\subsection{Study Objective}

The objective of the study was to investigate the oral communication challenges encountered during classroom interaction in the instruction of English language in secondary school classes in Kenya

\subsection{Theoretical Framework}

The study was based on the interaction hypothesis by Michael Long (1983) which offers an explanation how ESL learners can best succeed at learning a target language. Second language development can be facilitated through interaction between non-native speakers and native speakers or non-native speakers of a higher level by creating a naturalistic second language acquisition environment, therefore providing awareness of L2 gaps through negotiation of meaning. He argues that conversation interaction is essential if not sufficient condition for second language acquisition. He studied the ways in which speakers modify their speech and their interaction patterns in order to help learners participate in a conversation or understand meaning in a new language.

\section{Literature Review}

In this section literature related to oral communication challenges encountered in English language classes during classroom interaction and how they influence the teaching and learning of English as a second language has been presented.

\subsection{Oral Communication Challenges in English Language Classes}

Thornbury (2007) points out that an English course should create optimal conditions for developing learners' sociocultural knowledge, that is "the culturally embedded rules of behaviour" and their linguistic knowledge, which includes discourse and speech act knowledge and knowledge of the grammar, vocabulary, and phonology of the target language. These knowledge ideas must then be appropriately activated in order to be made available for using regular speaking practice in the classroom and beyond. These knowledge ideas can only be made available to the learners in class through oral communication. Therefore, oral language plays a significant role in classroom interaction as it is the most frequently used medium of communication. It is the primary medium through which classroom discourse takes place.

She further asserts that as far as the stages of mental processing involved in speaking are concerned, there is not much difference between native and target languages. Both combine the processes of conceptualization, articulating selfmonitoring and negotiation. Yet, the skill of speaking is not automatically transferable from the speaker's first language into the second language. While commenting on Thornbury's assertion, Aleksandrak (2011) says even extensive knowledge of the target language's grammar and vocabulary often presented by advanced students of foreign language departments does not guarantee success in oral communication when this knowledge is not properly integrated or accessed.

Gathumbi, Bwire and Roy-Campell (2014) in their study, instructional practices and challenges in secondary English language teaching implication for development of benchmarks in Kenya reported that English language teachers revealed among the problems learners experienced in English language classrooms include: the Inability to read fluently and comprehend passages, spelling mistakes in the written work, influence of mother tongues which affects all other skills lack of exposure to rich environments, overloaded curriculum that does not give enough time to do in-depth study, inability to relate language and literature as one entity, pronunciation and speaking challenges that affect the quality of their reading, problems of understanding poetry and finally difficulty in inferring meaning without the use of dictionary.

In the same study the teachers gave the following reasons for the learners' inability to learn English: learners' poor reading background. This was said to emanate from the primary school preparation and learner's home background. Many learners leave school not having acquired the expected proficiency in English as a subject and language of instruction. Yet reading is critical to general development of language proficiency. Another reason is learner's attitude to learning English language. They found out that many learners have negative attitude towards leaning English as they believe it is difficult to master. This they reported may affect their ability to listen, speak read or write. They said that it is incumbent upon the teachers to use interesting teaching techniques that would help learners to develop the requisite skills to function effectively in English; finally, the introduction of vernacular radio stations in various local languages was reported to have reduced even further, learners' exposure to English. They reported that learners seemed to prefer listening to such radio stations and not to those that broadcast in English. They said that when the learners were asked why they prefer these stations, they said they understood better and enjoyed listening to the local programmes than when they listen to broadcast in English. They said that the learners could also associate with what they discussed.

Similarly, Aleksandrak (2011) citing Ur (1995) points out problems that are commonly observed in the language classroom are related to individual learners' personalities and attitudes to the learning process and learning speaking in particular. These are:

Inhibition- fear of making mistakes, losing face, criticism; shyness; nothing to say - learners have problems with finding motives to speak, formulating opinions or relevant comments; low or uneven participation-often caused by the tendency of some learners to dominate in the group and lastly mother tongue use- particularly common in less disciplined or less motivated classes, learners find it easy or more natural to express themselves in their native language (p. 121). 
She further asserts that the above situations occur in language classrooms regardless of the level of proficiency or the number of students in the group. Moreover, every learner enters any learning and communicative environments with his/her entire personality additionally shaped by their prior learning and communicative experiences, both positive and negative. This individual dimension is particularly noticeable among older and more advanced learners who often have good insight into the nature of their individual difficulties, an accurate assessment of the skills they have already developed and consequently, clearly defined needs.

Discussing the factors inhibiting the teaching of oral skills Onchera (2013) observes that teachers reported that several factors hindered the teaching of oral communication skills and learner participation during lessons. He said that majority of teachers cited learners' shy disposition as a major hindrance in the teaching of oral skills. Teachers said that most of the learners preferred to remain quiet allowing only the articulate ones to dominate. This they reported happened to most learners who when selected by the teacher know the correct answer to the question asked, but choose to keep quiet pretending not to know. Teachers also reported that mother tongue interference was another crucial factor hindering the teaching of oral skills alongside the learner's shyness. Most of the learners spoke mother tongue and this highly impacted on their performance in spoken English. Every time they attempted to answer a teacher's question, their accent was heavily loaded with the local languages so that in certain cases they were laughed at. This, the teacher said hindered learning, since those with this problem lacked confidence and refused to participate further. This showed that these learners lacked practice in English language and hence its expressive qualities.

He further pointed out that almost all teachers observed that away from class time, the learners' medium of communication was their first language. This attitude was seen to affect the learners' oral fluency when it came to communicating in English during their lessons. This, the teachers said contributed to their shyness which was observed to be the major hindrance to their oral participation in class. When the learners were given chances by the teachers to ask questions, none raised any questions due to shyness.

In the same vein Adaba (2017) in exploring the practice of Teacher - Student classroom interaction to develop the learners' speaking skills said that teachers reported that students experienced the following problems during oral expression: shyness, anxiety, and stress, low proficiency of the learners in the English language, teaching methodology; majority of the teachers had limited experience about CLT and they had used traditional type or teacher - centered English methodology, fear of making mistakes, nothing to say about the topic, limited vocabulary knowledge, low participation, mother tongue use, lack of background knowledge lack of or low confidence, lack of enough time, lack of appropriate activities in the students' text book, failures of the learners to use the language outside the class, different learners' learning styles and finally text lack of basis of certain communication functions.

Adaba further observes it is the teachers' responsibilities to create a supportive environment in class and encourage respect among students and to strengthen the students' confidents when speaking or doing oral presentations in front of others where their attention is more focused on communicating content than in accuracy of their speech. Scrivener (2005) while commenting on classroom interaction says the language classroom is rich in language for learners, quite apart from the language that learners and teacher may suppose they are focusing on in the subject matter of the lesson. He notes that students learn a lot of their language from what they hear their teacher says: the instruction, the aside jokes, the chit chat, and the comments among others. He says that it would be unsatisfactory if the teacher's talk dominated the lesson to the exclusion of participation from as many learners as possible.

\section{Research Methodology and Design}

This study adopted mixed methods approach, thus utilizing quantitative and qualitative methods in the collection and analysis of data. Fraenkel and Wallen (2010) point out that mixed research approach can help clarify and explain relationships found to exist between variables. It also allows researchers to explore relationships between variables in depth and help to cross validate relationships discovered between variables. According to Creswell and Clark (2011, 2018) mixed methods research approach provides trends that offset the weakness of both qualitative and quantitative research. They also point out that mixed methods research gives more evidence for studying a research problem than either qualitative or quantitative research alone. Finally, it helps to answer questions that cannot be answered by quantitative and qualitative approaches alone. The study adopted descriptive research design. According to Bhattacharjee (2012) survey research involves the use of standardized questionnaires or interviews to collect data about people and their preferences, thoughts and behaviours in systematic manner.

Simple random sampling technique was used to select a total of 13 out of 112 schools that engaged in the study, while form three classes were purposely selected for the study. Fifteen form three students from each of the selected classes were randomly selected to fill in the students' questionnaire giving a total of 195 students. The form three students were chosen on the assumption that their language ability is sufficiently developed and they can interact well using English language in class. The teacher of English from the selected class in each school automatically participated in the study. In total 13 teachers of English participated in the study

\subsection{Research Instruments}

In the study a combination of a combination of three instruments was adopted to collect both qualitative and quantitative data. These are interview guide for teachers of English, classroom observation schedule and student questionnaire. The main purpose for using the three instruments was to triangulate the findings of the study. 


\subsection{Data Analysis Procedures}

Quantitative data drawn from closed ended items in the student questionnaire was analyzed using descriptive statistics with the help of Statistical Package for Social Sciences. Creswell and Clark $(2011,2018)$ observe that quantitative data analysis proceeds from descriptive analysis to inferential analysis and multiple steps in the inferential analysis build a greater refined analysis. The data was compiled in frequencies and then converted into percentages. For easy interpretation, the information was tabulated. Information from open ended items was analyzed qualitatively into themes guided by the study objectives.

Qualitative data obtained from open ended items in the student questionnaire, teacher interview guide, classroom observation schedule were coded and analyzed descriptively in identified themes based on study objectives as (Kumar 2011; Creswell and Clark, 2011, 2018) point out qualitative data analysis involves coding the data, dividing the text into small units that is phrases, sentences or paragraphs, assigning a label to each unit and then grouping the codes into themes and finally a discussion of evidence for the themes or categories; or diagrams presenting frameworks, models or theories.

\section{Findings of the Study}

The purpose of this study was to investigate the oral communication challenges encountered by learners in English language classes during classroom interaction in the instruction of English language in secondary schools in Elgeyo Marakwet County, Kenya

\subsection{Oral Communication Challenges in English Language Classes}

Some of the oral communication challenges that the teachers reported they encounter during classroom interaction are varied in nature. Most of the teachers interviewed reported that the most common problem learners face is difficulty in pronouncing words; when learners encounter such words which they cannot pronounce they either skip such words or abandon them completely, some of the learners do not participate during oral lessons; therefore there is uneven participation among the learners, some of the learners dominate classroom discourse while others just keep quite. Most teachers said this is a challenge because you cannot gauge the level of understanding of all the learners in class. It is also difficult for a teacher to find out if a certain concept or aspect of language has been understood by all the learners. They also reported that some students also do not seek for clarification or ask questions if they do not understanding what the teacher is teaching. One teacher reported:

Majority of the learners in my class especially the slow learners do not seek for clarification or ask questions if they have not understood what I am teaching them. It is therefore very difficult for me to find out whether they have understood what I am teaching or not.

Other challenges reported by the teachers include shyness by some students. Teachers said that shy students do not want to speak for example during class discussion, some students also find it difficult answering questions if they are not sure of the answers; they fear other learners might laugh at them.

In the English language classes it was observed that there are various challenges encountered during oral communication during classroom interaction. The cause of these oral communication challenges can be attributed to both the teachers and the learners. It was observed that some of the teachers dominated classroom talk; this was evident mostly in those situations where the learners could not open up during class interaction. It also happens when the teacher is introducing a new concept or a new topic which is not familiar to the learners. Some of the teachers were also seen to select particular learners many times to participate in class at the expense of the other students. The teachers were often seen to favour those learners who raise up their hands; this created uneven participation among the learners.

In the study it was also observed that most of the learners refuse to participate in class; most of them just keep quiet, they do not raise up their hands to participate during lessons, this hinders oral communication. Those students who refuse to speak sit mostly at the back row of the class where they assume the teachers cannot notice them. In relation to this some students only participate when the teacher asks them to do so. Others when asked to answer question say 'what they wanted to say has been said by an earlier speaker or they say 'they do not have an answer'. These oral communication challenges therefore affect classroom interaction in one way or another as the teachers face challenges when giving instruction to the learners. When learners refuse to participate it becomes difficult for the teacher to gauge their understanding, language use, communicative competence and finally their linguistic competence.

In the student questionnaire when the learners were asked 'do you sometimes experience oral communication challenges in your English language classes?' From the study, majority of the learners 153 (78.5\%) reported that they sometimes experience oral communication challenges in their English language classes, while $42(21.5 \%)$ reported that they do not experience oral communication challenges in their English language classes. It can thus be concluded that majority of the learners in secondary school classes experience oral communication challenges in their English language classes. This is summarized in Table 1.

\begin{tabular}{|c|c|c|}
\hline Opinion & Frequency & Percentage \\
\hline Yes & 153 & 78.5 \\
\hline No & 42 & 21.5 \\
\hline Total & 195 & 100 \\
\hline
\end{tabular}

Table 1: Students' Experience of Oral Communication Challenges in English Language Classes 


\subsection{Causes of Oral Communication Challenges during Classroom interaction}

On the item 'what do you think is the cause of these oral communication challenges during classroom interaction?' A few of the teachers reported that because of the large class sizes they cannot reach out to all the learners in class as such most of the learners do not get a chance to participate. Most of the teachers interviewed reported that the cause of these oral communication challenges are varied for example most of the teachers said that most of the learners have limited vocabulary because of poor reading culture as most of the learners do not read extensively. Other reasons the teachers gave include the learner background; for example some teachers reported that learners who come from urban areas tend to speak out in class as opposed to those from rural areas, other teachers reported that some of the learners have negative attitude towards English language as a subject; they have a feeling that English is a difficult subject.

Other teachers pointed out that some of their students do not practice speaking English in and outside class. In addition, some teachers reported that it occurs because of personality of the learners; most learners who are extroverts like dominating discussions in class as such they participate more often than the introverts, this contributes to uneven participation by the learner in English language classes. Finally a few teachers reported that they do not have to teach oral work because there are deadlines to meet for example syllabus coverage others said the integrated syllabus is a challenge in itself as it requires teacher to handle both English language and literature at the same time.

The learners reported that they experience these oral communication challenges because they do not understand some of the English words and phrases their teachers use in class. They also reported that some teachers use complicated English. Others reported that they experience challenges pronouncing certain English words as such they fear their peers laughing at them, in such situations they experience communication breakdown as they either skip reading a text loudly or abandon speaking and just keep quiet or they sometimes code switch to either Kiswahili or colloquial language or mother tongue. Others reported that the English language has a variety of words with some that they have never encountered before. The learners reported that they experience these challenges because they do not read widely and therefore their vocabulary repertoire is limited. Others said that they do not practice speaking in English in and outside class. Others said that they lack self-confidence, others said that they experience these challenges because of the influence of other languages that is mother tongue and Kiswahili and 'Sheng'. Other learners reported that they are not articulate and hence they are shy to speak in English. Finally a few of the learners reported that they are not attentive in class.

\subsection{Areas Where Learners Experience Oral Communication Challenges During Classroom Interaction}

On the question 'state the areas you experience these oral communication challenges?' From the study most of the learners reported that they experience these oral communication challenges when they are giving a speech in class, during class presentation; they said that they at times experience challenges constructing correct sentences or pronouncing some words well. Others learners said that they experience challenges during class debates, others reported that they experience challenges when reading exerts from set books or comprehension passages loudly; they at times encounter words that they cannot pronounce well. Others learners reported that they experience challenges when having dialogue with their teachers, when asking and answering oral questions. Finally, others reported that they experience challenges when reciting poetry in class and also when narrating oral narratives in class.

\subsection{Ways of Minimizing Oral Communication Challenges during Classroom Interaction}

When asked to suggest some of the ways they could use to minimize these oral communication challenges, most of the teachers interviewed reported that the students should be encouraged to read widely in order to build their vocabulary and confidence in language use, others reported that they should boost the learners confidence by providing corrective feedback instead of pointing out the mistakes they make in class. Others teachers suggested that all the students should be encouraged to participate during class, teachers should employ learner centered teaching techniques where learners can participate in debates, discussions, use of drama.

In addition, the teachers suggested that they should use audio materials when teaching speaking and listening to enable them listen in order to motivate the learners in class. Other teachers said that schools should have functional language policies where the learners speak English most of the time when they are in school in order to their proficiency in English language. Others reported that all the learners in class should be given equal opportunities to speak instead of teachers choosing the same students to answer questions most of the time. In relation to this, teachers should be friendly to their learners; this will encourage the learners to speak out in class. Finally, teachers should reenergize subject support clubs for example debating and drama clubs; this they say will allow the learners to use English away from the normal class routine thus building their confidence and proficiency in spoken English.

On the question, 'what do you suggest to be done in order to minimize these oral communication challenges?' From the study most of the learners suggested that they should read novels, newspapers, magazines and plays widely in order for them to increase their stock of English vocabulary and learn how various writers use these words in their writings; they will also be exposed to various ways in which writers construct correct sentences. Other learners suggested they should participate in debates, public speaking, and drama while in school; this they said will go a long way in enhancing their linguistic and communicative competence and fluency in English language.

Apart from that they suggested that they should participate regularly in class discussions. They should also participate in asking and answering questions. Others suggested that they should use English most of the time in and outside class. Others said that they should avoid mixing languages during lessons for example using English and Kiswahili at the same time. These scenarios greatly influence their communicative competence in English language as it leads to pronunciation of English words like mother tongue words. Some of the learners suggested that their teachers should give them opportunities to participate in class. Teachers for example can organize inter- class symposiums and presentations 
instead of them giving lectures in class especially during literature lessons. Others reported that teachers should identify those areas where learners are weak in and work on those areas in order to improve learners' oral communication challenges.

In addition, to the above suggestions other learners said that their teachers should be good role models by using English all the time while in school; this they say will encourage the students to emulate them. Others said that their teachers should be friendly to them so that they can speak in their presents instead of just keeping quiet when their teachers are around for fear of making errors in presents of their teachers. Finally, the learners suggested that there should be a language policy in school where the learners should speak in English in and outside the school.

\subsection{Discussion of the Findings}

The students' questionnaire revealed that majority of the learners $153(78.5 \%)$ reported that they sometimes experience oral communication challenges in their English language classes. They reported that they experience these challenges because they do not understand some of the English words and phrases their teachers use in class. These findings add to those of Muter, Hulme, Snowling and Stevenson (2004) who point out that word recognition senses critically depend on phonological processes (particularly phonemic sensitivity, and letter knowledge) while reading comprehension is dependent on higher- level language skills (vocabulary knowledge and grammatical skills). They also reported that some teachers use complicated English. Others reported that they experience challenges pronouncing certain English words as such they fear their peers laughing at them; in such circumstances they experience communication breakdown as they either skip reading a text loudly or abandon speaking and they just keep quiet or they sometimes code switch to either Kiswahili, 'Sheng' or mother tongue. Muriungi and Kibui (2015) observe that teachers reported that majority of their students make pronunciation errors while reading aloud or when participating in class discussions.

Other learners reported that the English language has a variety of words in which some of them they have never encountered before. The teachers' interview corroborates this. Most of the teachers interviewed reported that the most common problem their learners face in class is difficulty in pronouncing some English words, the teachers reported that when the learners encounter such words that they cannot pronounce they either skip or abandon them completely. These findings support those of Gathumbi et al. (2014) who established that in Kenya teachers reported that learners are faced with the inability to read fluently and comprehend passages, pronunciation and speaking challenges among others.

The leaners' questionnaire revealed that the learners experience oral communication challenges because they do not read widely and therefore their vocabulary repertoire is limited. Brown, (2001) says that as learners interact with each other through oral and written discourse, their communicative abilities are enhanced. Pica (1994) and also Hall (1993) point out that this interaction also creates the opportunity for learners to negotiate to have increased chances for comprehension of the target language, and to acquire target discourse conventions and practice higher level academic communicative skills.

In addition, other learners reported that they do not practice speaking in English in and outside class. Others said that they lack self-confidence; others reported that they experience these challenges because of the influence of other languages that is mother tongue Kiswahili and 'Sheng'. Kisaka (2015) points out learners in both primary and secondary school reported that the major cultural practice that influences mastery of English language was the frequent use of Kiswahili and mother tongue for communicating at home.

Finally, other learners reported that they are not articulate in spoken English and hence they are shy to speak in English. These findings are consistent with those of Adaba (2017) who found out that the speaking problems most students face in oral expression according to the teachers 'explanations include: large class sizes, shyness, anxiety and stress, low proficiency of the learners in the English language and methodology; majority of the teachers had limited experiences about CLT and they had used traditional type or teacher- centered English teaching methodology.

Other challenges affecting classroom interaction include fear of making mistakes, nothing to say, limited vocabulary knowledge, students' low proficiency in English language, failures of the learners to use the language outside the class, low participation, mother tongue use, lack of background knowledge, lack of low confidence, lack of enough time, lack of appropriate activities in students' text, different learner's learning styles and finally textbooks lacking certain communicative functions. These add to the findings of Ur (1995) who points out that the problems observed in English language classrooms include inhibition- fear of making mistakes, losing face, criticism; shyness; nothing to say - learners have problems with finding motives to speak, formulating opinions or relevant comments; low or uneven participationoften caused by the tendency of some learners to dominate in the group; mother tongue use- particularly common in less disciplined or less motivated classes, learners find it easy or more natural to express themselves in their native language.

During the teachers' interview the teachers reported that the cause of these oral communication challenges are varied for example most of the teachers reported that most of the learners have limited vocabulary because of poor reading culture as most of the learners do not read extensively. These findings are in line with those of Aleksandrak (2011) who asserts that every learner enters any learning and communicative environment with his/her entire personality additionally shaped by their prior learning and communicative experiences both positive and negative.

Other reasons given by the teachers as what they think is the cause of these coral communication challenges includes learner background; some teachers reported that learners who come from urban areas tend to speak out in class as opposed to those from rural areas, others reported that some of the learners have negative attitude towards English language as a subject. Others do not practice speaking English in and outside class. These findings are consistent with those of Gathumbi et al., (2014) who established that one of the reasons why learners find it difficult learning English is because of their attitude to learning English. They found out that many learners have negative attitude towards learning 
English as they believe it is difficult to master. This they reported may affect their ability to listen, speak, read or write. They said that it is incumbent upon the teachers to use interesting teaching techniques that would help learners to develop the requisite skill to function effectively in English.

The teachers' interview further revealed that other causes of oral communication challenges during classroom interaction are learner's personality; teachers reported that learners who are extroverts dominate class discussions in class as such they participate more often than the introverts; this contributes to uneven participation in English language classes. These findings are consistent with those of Onchera (2013) who observes that teachers reported that several factors hindered the teaching of oral communication skills and learner participation during lessons. He said that majority of teachers cited learners' shy disposition as a major hindrance in the teaching of oral skills. Teachers said that most of the learners preferred to remain quiet allowing only the articulate ones to dominate. This they reported happened to most learners who when selected by the teacher know the correct answer to the question asked, but choose to keep quiet pretending not to know. This is collaborated by the findings of the classroom observation where it was observed that some of the teachers dominated classroom talks; this was evident mostly in those situations where the learners could not open up during class interaction.

It was also observed when a teacher is introducing a new concept or a new topic which is not familiar to the learners. Some of the teachers were also seen to select some specific learners many times to participate in class many times. Teachers were seen to only choose those learners who carry up their hands; this situation therefore created uneven participation among the learners in class. These findings support those of Scrivener (2005) who observes:

The language classroom is rich for language for learners, quite apart from the language that learners and teacher may suppose they are focusing on in the subject matter of the lesson. Students learn a lot of their language from what they hear the teacher say: the instructions, the discussions, the asides jokes, the chit-chat, the comments etc. It would be unsatisfactory if the teacher's talk dominated the lesson to the exclusion from as many learners as possible (p. 84).

Teachers in English language class should create a relaxed learning environment in the classroom where all learners can participate in classroom activities. Teachers should avoid the temptation to talk much in class as this will lead them to dominate talks in the classroom therefore inhibiting students' participation.

\section{Conclusion}

The challenges that learners experience in English language classes include inability to understand some English words and phrases that their teachers use in class, inability to pronounce certain English words. The learners experience these challenges because they do not read widely and therefore their vocabulary repertoire is limited, they do not practice speaking English in and outside class, they lack confidence, influence of other languages and finally lack of being articulate in spoken English and hence they are shy to speak English in front of other learners.

\section{References}

i. Adaba H. W. (2017). Exploring the Practice of Teacher-Student Classroom Interaction in EFL to Develop the Learners' Speaking Skills in Tullu Sangota Primary School Grade Eight Students in Focus. Arts Social Sci J 8: 295. doi: 10.4172/2151-6200.1000295

ii. Aleksandrzak, M. (2011). Problems and challenges in teaching and learning speaking at advanced level. Glottodidactica Xxxvii: 37-48

iii. Davies, P, \& Pearse, E. (2000). Success in English Teaching. Oxford University Press

iv. Bhattacherjee, A. (2012). Social Science Research: Principles, Methods, and Practices, (2 ${ }^{\text {nd }}$ Edition) University of South Florida Scholar Commons: Florida

v. Creswell, J. W \& Clark, V. L. P. (2018). Designing and Conduction Mixed Method Research. (Third Edition) Los Angeles: SAGE Publications

vi. $\quad$ Fraenkel, J.R \& Wallen, N.E. (2010). How to Design and Evaluate Research in education (7th edition). International edition. New York: McGraw-Hill Companies Inc

vii. Gathumbi, A. M. W, Bwire, A. M \& Roy- Campell, Z.M. (2014). Instructional Practices and Challenges in English language teaching: implication for development of benchmarks in Kenya. researchjournalis Journal of Education Vol. 2 No. 11, 1-16

viii. Kisaka, J. (2015). Cultural Factors Hindering Mastery of English Language in Primary and Secondary Schools: A Case of Kilifi County, Kenya. British Journal of Education 3 (2), 38-44

ix. Kumar, R. (2011). Research Methodology: a step-by-step guide for beginners (3rd Edition) New York /London: Sage

X. Long, M. H. (1983). Native speaker / non-native speaker conversation and the negotiation of comprehensible input. Applied Linguistics, Vol. 4, pp.126-141.

xi. Morreale, S.P, Osborn, M. M \& Pearson, J. C. (2000). Why Communication is Important: A Rationale for Centrality of the Study of Communication. Journal of the Association for Communication Administration 29, 1-25

xii. Muriungi, P, K \& Kibui, M, K. (2015). The influence of Motivation on Acquisition of English Language Skills among Day Secondary School Students in Imenti South District Kenya. International Journal of Research in Humanities and Social Studies V 2 (5) pp. 52- 58

xiii. Onchera, P. 0. (2013). The pedagogical hindrances to oral communication skills in English in Kenya: a case of secondary schools in Kisii County. Educational Research Vol. 4(7) pp. 536-542, Available online@ http://www.interesjournals.org/ER

xiv. Scrivener, J. (2005). Learning Teaching: A Guide Book for English Language Teachers (Second Edition) London. Macmillan 
xv. Thornbury, S. (2007). How to Teach Speaking. Harlow: Pearson Education Limited.

xvi. Ur, P. (1995). A Course in Language Teaching. Practice and Theory. Cambridge: Cambridge University Press.

xvii. Yule, G. (2010). The Study of Language (4th edition). New York: Cambridge University Press 